\title{
Estimation of genetic parameters and genetic changes for growth characteristics of Santa Ines sheep
}

\author{
E.L. Aguirre ${ }^{1,2}$, E.C. Mattos ${ }^{1}$, J.P. Eler ${ }^{1}$, A.D. Barreto Neto ${ }^{3}$ and J.B. Ferraz ${ }^{1}$ \\ ${ }^{1}$ Grupo de Melhoramento Animal e Biotecnologia, \\ Faculdade de Zootecnia e Engenharia de Alimentos, Universidade de São Paulo, \\ Campus "Fernando Costa", Pirassununga, SP, Brasil \\ ${ }^{2}$ National University of Loja, Loja, Provincia Loja, Ecuador \\ ${ }^{3}$ Associação Sergipana dos Criadores de Caprinos e Ovinos, Aracaju, SE, Brasil \\ Corresponding author: E.L. Aguirre \\ E-mail: leninaguirrer@yahoo.es / leninaguirrer@usp.br
}

Genet. Mol. Res. 15 (3): gmr.15038910

Received June 22, 2016

Accepted July 26, 2016

Published August 18, 2016

DOI http://dx.doi.org/10.4238/gmr.15038910

Copyright $(\subset 2016$ The Authors. This is an open-access article distributed under the terms of the Creative Commons Attribution ShareAlike (CC BY-SA) 4.0 License.

\begin{abstract}
Studying genetic parameters and genetic changes in Santa Ines sheep is important, because it is the commonest breed in Brazil. This study obtained genetic data from 37,735 pedigree records of lambs over 12 years (2003-2014) from 33 flocks in 10 Brazilian States; 11,851 records of performance were available. (Co)variance components, genetic parameters and breeding values estimates were obtained by derivative-free restricted maximum likelihood in a univariate analysis that included maternal additive genetic and maternal permanent environmental effects. Birth weight, weaning weight, weight at 180 days of age, weight at 270 days of age, average daily weight gain in the following states: from birth to weaning, from weaning to 6 months, from 6 months to 9 months, and from weaning to 9 months; presence of
\end{abstract}


hair in fur and leg muscularity were assessed. (Co)variance component values increased in the weight traits with age. A significant maternal effect was found in the pre-weaned stage that decreased in the postweaned stage. High values were estimated for the maternal permanent environmental effect, possibly because of the extensive grassland that was available. High total heritability values were estimated for all of the traits evaluated. Significant, positive correlations were found between direct and maternal additive genetic traits with a gradual decrease as the lambs gained independence from their mothers. The genetic trends observed were irregular and incremental. Significant genetic variance suggests that direct selection for pre-weaning traits results in indirect selection of maternal abilities, and individual selection of any postweaning trait results in rapid genetic improvement.

Key words: Brazilian sheep; Heritability; Genetic gain; Body weight

\section{INTRODUCTION}

Santa Ines is currently the most common sheep breed in Brazil. These sheep originated in the State of Bahia and other states of the Brazilian Northeast, from crossbreeding mainly among the Bergamácia, Morada Nova and Somali breeds. They are well-adapted to tropical environments and are widely distributed in the North and Northeast regions. In the last decade, flocks have expanded greatly in number in all of the states of Brazil and in certain other countries of South America, Mexico and South Africa (Silva et al., 2012; Santana Jr et al., 2013). It is important to study the genetics of the economically relevant traits of this breed, which is increasing in popularity for meat and skin production because of its adaptability to different environments.

In any system of livestock production, large numbers of animals are desired, and production depends not only on improving the environmental conditions of the animal but also on improving production efficiency by increasing weight gain in the pre- and post-weaning stages (Mohammadi et al., 2015). Therefore, improving the genetic quality of the flock through selection is necessary, as is estimating genetic parameters as precisely as possible, and taking into account direct genetic, maternal, and permanent environmental effects with respect to body weight traits. Pre-weaning body weight traits are particularly important (Tamioso et al., 2013; Carvalho et al., 2014; Gholizadeh and Ghafouri-Kesbi, 2015; Jannoune et al., 2015), as the maternal effect decreases with increasing age (Mohammadi et al., 2015). Taking these factors into account prevents selection bias, which may decrease efficiency.

According to Maniatis and Pollott (2003), a database composed of incomplete pedigree information, particularly of female sheep, will cause prediction errors in genetic estimates. Several studies have been conducted in Brazil that have estimated the genetic parameters of Brazilian sheep using small databases and short time periods, including the Brazilian Somali breed (Magalhães et al., 2013), the Sul-Mato-Grossense breed (Oliveira et al., 2014), and the Morada Nova breed (Shiotsuki et al., 2014).

Another point to consider according to Maniatis and Pollott (2002), and confirmed by Santana et al. (2013), is that accurate estimates are only achieved by using models that include genotype-environment interactions. Therefore, estimates obtained from homogeneous

Genetics and Molecular Research 15 (3): gmr.15038910 
environments do not guarantee genetic improvement in heterogeneous environments (Carvalho et al., 2014). The primary objective of this study was to obtain accurate estimates of genetic parameters and genetic trends of growth traits in Santa Ines sheep in different regions of Brazil. Leg muscularity and hair in fur were also included in this study, as these potentially meaningful traits have not been considered in other studies.

\section{MATERIAL AND METHODS}

\section{Data and management}

The database used belongs to the Associação Sergipana dos Criadores de Caprinos e Ovinos (ASCCO, Sergipe State Association of Goat and Sheep Breeders), and is used by the ASCCO/USP, Program for Animal Genetic Evaluation, which is led by the Animal Breeding and Biotechnology Group of FZEA-USP in Pirassununga, State of São Paulo, Brazil. Pedigree information of 37,735 animals and phenotypic trait records of 11,851 lambs that descended from 411 sires and 5,298 dams were used. The data were collected over 12 years (20032014) from 33 farms in 10 Brazilian states between $9^{\circ} \mathrm{S}$ and $26^{\circ} \mathrm{S}$ latitude and $40^{\circ} \mathrm{W}$ to $60^{\circ} \mathrm{W}$ longitude. The flocks lived on grassland throughout the year, where native pasture plays an important role in animal feeding, particularly in the Northeast region. The pastures contained Brachiaria spp, Cynodon spp, Cenchrus ciliaris and Panicum maximum grasses. Most farms provided mineral supplements and proteins to the animals, particularly in the dry season. Lambs were weaned at approximately 60 days of age (ASCCO, 2014).

The following weight traits were assessed: birth weight (BW), weaning weight at 60 days of age (WW), weight at 180 days of age (W180), weight at 270 days of age (W270), average daily weight gain from birth at weaning (DGW), average daily weight gain from weaning to 6 months (DGWS), average daily weight gain from 6 months to 9 months (DGSN), and average daily weight gain from weaning to 9 months (DGWN). In addition, visual appraisals of the presence of wool or hair in the fur (HF) and leg muscularity (LM) were conducted. The first eight characteristics were measured in numerical units $(\mathrm{kg})$, while HF and LM were visual evaluations made at 9 months of age using a score of 1 to 5 for LM (where a higher score indicates greater muscularity), and a score of 1 to 6 for HF (where a higher score indicates "short hair", which is more appropriate for tropical conditions). These two traits are being increasingly measured in the Breeding Program of Santa Ines sheep (ASCCO/USP, 2011). Outlier records with \pm 3 standard deviations from the average for BW, WW, W180, and W270 were excluded from the analysis.

\section{Statistical analysis}

The data were first assessed by analysis of variance using the Statistics Program R (R Core Team, 2016), in order to identify the fixed effects to be included in the model. Nongenetic effects, such as sex (male or female), type of lambing (single or twins), year (20032014), season (dry or wet), flock location (33 breeders), and maternal age (that ranged from 9 to 205 months and was delineated into 16 levels), were analyzed. Maternal age was only statistically significant $(\mathrm{P}<0.05)$ for $\mathrm{BW}$, WW and DGW and to a higher $\alpha$ level $(\mathrm{P}<0.01)$ for W180 and DGWS. HF was significantly affected by sex but not by type of lambing. With these exceptions, the effects were similarly significant $(\mathrm{P}<0.05)$ for the 10 characteristics studied;

Genetics and Molecular Research 15 (3): gmr.15038910 
therefore, they were all included in the variance component estimation. Characteristics of the data structure, summary statistics and the effects of several non-genetic factors on each trait are summarized in Table 1.

Table 1. Characteristics of the data structure, summary of statistics, and significance of the source of variation for growth traits of Santa Ines sheep.

\begin{tabular}{|c|c|c|c|c|c|c|c|c|c|c|}
\hline Trait & BW & W60 & W180 & W270 & DGW & DGWS & DGSN & DGWN & $\mathrm{HF}$ & LM \\
\hline No. records & 11,851 & 6,708 & 5,254 & 3,683 & 6,933 & 4,126 & 2,792 & 3,081 & 3,228 & 3,159 \\
\hline No. contemporary groups & 255 & 208 & 204 & 176 & 198 & 156 & 141 & 141 & 146 & 145 \\
\hline \multicolumn{11}{|l|}{ Summary of statistics } \\
\hline Mean $(\mathrm{kg})$ & 3.64 & 14.6 & 31.7 & 38.5 & 0.166 & 0.144 & 0.093 & 0.116 & $4.37^{1}$ & $2.4^{1}$ \\
\hline Standard deviation $(\mathrm{kg})$ & 0.84 & 5.03 & 10.7 & 13.7 & 0.07 & 0.071 & 0.068 & 0.06 & $1.2^{1}$ & $0.93^{1}$ \\
\hline $\mathrm{CV} \%$ & 22.9 & 34.4 & 33.9 & 35.5 & 41.9 & 48.9 & 73.7 & 50.2 & 27.8 & 39.1 \\
\hline \multicolumn{11}{|l|}{ Effects $^{2}$} \\
\hline Contemporary groups (flock-year-season) & $* *$ & $* *$ & $* *$ & $* *$ & $* *$ & $* *$ & $* *$ & $* *$ & $* *$ & $* *$ \\
\hline Type of birth & $* *$ & $* *$ & $* *$ & $* *$ & $* *$ & ** & $* *$ & $* *$ & NS & $* *$ \\
\hline Sex & $* *$ & $* *$ & $* *$ & $* *$ & $* *$ & $* *$ & $* *$ & $* *$ & * & $* *$ \\
\hline Age of dam (covariate) & $* *$ & $* *$ & $*$ & NS & $* *$ & * & NS & NS & NS & NS \\
\hline Age of lamb (covariate) & & $* *$ & *** & $* *$ & $* *$ & ** & $* *$ & $* *$ & $* *$ & $* *$ \\
\hline
\end{tabular}

${ }^{1} \mathrm{HF}$ score 1-6, where a higher score reflects short hair that is more appropriate for tropical conditions; LM score $1-5$, where a higher score indicates greater muscularity. ${ }^{2}$ Indicates the significance of the source of variation. ${ }^{*} * \mathrm{P}<$ $0.05,{ }^{*} \mathrm{P}<0.01$; NS, not significant. $\mathrm{CV}$, coefficient of variation; BW, birth weight; W60, weight at weaning or at 60 days; W180, weight at 180 days; W270, weight at 270 days; DGW, daily weight gain at weaning; DGWS, daily weight gain from weaning to 6 months; DGSN, daily weight gain from 6 to 9 months; DGWN, daily weight gain from weaning to 9 months; HF, hair in fur; LM, leg muscularity.

The effects of flock, year, and season formed contemporary groups, so the fixed effects used were contemporary group, sex, and type of lambing. Lamb age at the time of measurement was included as a covariate in the models for its linear and quadratic effects. Ewe age at lambing was also included as a covariate, but only for BW, WW, W180 and DGW. Animal, maternal, maternal permanent environmental, and residual direct effects were included as random effects. A mixed model methodology was used, which was specific for each variable in the single-trait animal model analysis conducted. An inclusive model (Equation 1) included maternal additive genetic effects and maternal permanent factors for BW, WW, W180, and DGW. For W270, DGWS, DGSN, DGWN, HF, and LM, maternal and permanent environmental effects were not included in the model (Equation 2):

$$
\begin{array}{cr}
Y=X \beta+Z_{a} \alpha+Z_{m} m+W \rho+e & \text { (Equation 1) } \\
Y=X \beta+Z_{a} \alpha+e & \text { (Equation 2) }
\end{array}
$$

where $Y$ is the vector of records; $\beta, \alpha, m, \rho$ and $e$ are fixed vectors, direct additive genetic effect, maternal additive genetic effect, permanent environment effect on the dam and residual effect, respectively; with incidence matrices $X, Z_{a}, Z_{m}$, and $W$ that relate these effects to the records.

The (co)variance components, genetic parameters and breeding values (BVs) were obtained using the derivative-free restricted maximum likelihood (DFREML) method (Graser et al., 1987) in the multiple-trait DFREML program (Boldman et al., 1995). Each analysis was 
restarted several times with different initial prior values to ensure that the value of estimates corresponded to the absolute maximum of the likelihood function. If the estimates did not change, the convergence criterion was confirmed when the variance value was $-2 \log L$ ( $L$ was the likelihood function, which was calculated based on the last five iterations if the simplex was less than $\left.10^{-9}\right)$.

(Co)variance components of the phenotypic variance $\left(O_{p}^{\prime 2}\right)$, which was the sum of the direct genetic additive variance $\left(O_{a}^{\prime 2}\right)$, maternal additive genetic variance $\left(O_{m}^{\prime 2}\right)$, directmaternal covariance $\left(\sigma_{a m}\right)$, variance due to permanent environmental effect $\left(O_{p e}^{\prime 2}\right)$, and residual variance $\left(O_{e}^{\prime 2}\right)$, were derived to convergence after they were used to obtain the direct additive heritability $\left(h_{a}^{2}\right)$, maternal heritability $\left(\mathrm{h}_{m}^{2}\right)$, and the proportion explained by the permanent environmental effect of the total variance $\left(p e^{2}\right)$. These were obtained by dividing $O_{a}^{\prime 2}, O_{m}^{\prime 2}$ or $O_{p e}^{\prime 2}$, respectively, by $O_{p}^{\prime 2}$.

The direct-maternal correlation $\left(\mathrm{r}_{\mathrm{am}}\right)$ was calculated in the following manner:

$$
r_{a m}=\sigma_{a m} / \sqrt{\sigma_{a}^{2} \times \sigma_{m}^{2}}
$$

Total heritability was estimated by the following formula (Willham, 1972):

$$
\mathrm{h}_{\mathrm{T}}^{2}=\left(\sigma_{\mathrm{a}}^{2}+0,5 \sigma_{\mathrm{m}}^{2}+1,5 \sigma_{\mathrm{am}}\right) / \sigma_{\mathrm{p}}^{2}
$$

The total maternal effect $\left(\mathrm{t}_{\mathrm{m}}\right)$ was calculated in order to estimate the repeatability of ewe performance (Mandal et al., 2012; Mohammadi et al., 2015), using the following formula (Notter, 1998):

$$
t_{m}=\frac{1}{4} h_{a}^{2}+h_{m}^{2}+p e^{2}+\left(m r_{a m} h\right)
$$

\section{RESULTS AND DISCUSSION}

\section{Descriptive statistics of the traits analyzed}

The mean \pm SD values of BW, WW, W180, W270, DGW, DGWS, DGSN, DGWN, $\mathrm{HF}$, and $\mathrm{LM}$ were $3.64 \pm 0.84 \mathrm{~kg}, 14.6 \pm 5 \mathrm{~kg}, 31.7 \pm 10.7 \mathrm{~kg}, 38.5 \pm 13.7 \mathrm{~kg}, 0.17 \pm 0.07 \mathrm{~kg}$, $0.14 \pm 0.07 \mathrm{~kg}, 0.09 \pm 0.07 \mathrm{~kg}, 0.12 \pm 0.06 \mathrm{~kg}, 4.4 \pm 1.2$, and $2.4 \pm 0.9$, respectively (Table 1). Another population of Santa Ines sheep had a similar mean for BW (Carvalho et al., 2014). A comparison of these performances with those recorded in other Brazilian breeds (Magalhães et al., 2013; Shiotsuki et al., 2014) and "local" breeds from other parts of the world was conducted (Mandal et al., 2012; Shokrollahi and Baneh, 2012; Gholizadeh and GhafouriKesbi, 2015; Gowane et al., 2015; Mohammadi et al., 2015). The Santa Ines breed had a growth performance that was similar to or better than that of the other breeds. No references exist for HF (4.4) or LM (2.4), but these results suggest the importance of improving the process of selection and evaluation, particularly for LM.

Genetics and Molecular Research 15 (3): gmr.15038910 


\section{(Co)variance components and genetic parameters}

The results presented in Table 2 show an incremental increase in (co)variance component values for the weight traits according to the age of the animal. Magalhães et al. (2013), Oliveira et al. (2014) and Jannoune et al. (2015) reported similar estimates. These results indicate that additive genetic variation exists between animals in which age, 270 days in this case, improves selection. Positive direct-maternal covariance was estimated in accordance with other studies (Gholizadeh and Ghafouri-Kesbi, 2015; Mohammadi et al., 2015). However, it is necessary to consider that other studies have reported $\mathrm{s}_{\mathrm{am}}$ negative (Shokrollahi and Baneh, 2012; Carvalho et al., 2014; Boujenane et al., 2015; Gowane et al., 2015). These results, according to Szwaczkowski et al. (2006), could arise from the omission of maternal effects from the evaluation, the type of management used (Eler et al., 1995), the breed analyzed (Dodenhoff et al., 1999), the structure of the dataset or the pedigree used (Maniatis and Pollott, 2003).

\begin{tabular}{|c|c|c|c|c|c|c|c|c|c|c|c|c|}
\hline \multirow[t]{2}{*}{ Trait } & \multicolumn{6}{|c|}{ (Co)variance components } & \multicolumn{6}{|c|}{ Genetic parameters } \\
\hline & $O_{a}^{\prime 2}$ & $O_{m}^{\prime 2}$ & $O_{p e}^{\prime 2}$ & $O_{e}^{2}$ & $O_{p}^{\prime 2}$ & $\sigma_{a m}$ & $h_{a}^{2}$ & $h_{m}^{2}$ & $p e^{2}$ & $r_{a m}$ & $h_{T}^{2}$ & $t_{m}$ \\
\hline BW & 0.111 & 0.071 & 0.284 & 0.031 & 0.497 & 0.027 & $0.22 \pm 0.04$ & $0.14 \pm 0.03$ & $0.57 \pm 0.03$ & 0.31 & 0.38 & 0.82 \\
\hline WW & 2.68 & 1.727 & 8.1 & 0.89 & 13.4 & 0.224 & $0.20 \pm 0.04$ & $0.13 \pm 0.05$ & $0.60 \pm 0.03$ & 0.10 & 0.29 & 0.80 \\
\hline W180 & 24.6 & 3.43 & 33.96 & 1.25 & 63.24 & 0.608 & $0.39 \pm 0.07$ & $0.05 \pm 0.02$ & $0.54 \pm 0.05$ & 0.066 & 0.43 & 0.70 \\
\hline W270 & 52.6 & - & - & 53.58 & 106.18 & - & $0.49 \pm 0.06$ & - & - & - & 0.49 & 0.12 \\
\hline DGW & 0.00119 & 0.00031 & 0.00151 & 0.00013 & 0.00314 & 0.0001 & $0.38 \pm 0.06$ & $0.10 \pm 0.01$ & $0.48 \pm 0.05$ & 0.17 & 0.48 & 0.61 \\
\hline DGWS & 0.00137 & - & - & 0.0018 & 0.00318 & - & $0.43 \pm 0.05$ & - & - & - & 0.43 & 0.11 \\
\hline DGSN & 0.00137 & - & - & 0.0018 & 0.00318 & - & $0.43 \pm 0.05$ & - & - & - & 0.43 & 0.11 \\
\hline DGWN & 0.00088 & - & - & 0.0011 & 0.00198 & - & $0.44 \pm 0.06$ & - & - & - & 0.44 & 0.11 \\
\hline $\mathrm{HF}$ & 0.368 & - & - & 0.94 & 1.307 & - & $0.28 \pm 0.05$ & - & - & - & 0.28 & 0.07 \\
\hline LM & 0.211 & - & - & 0.39 & 0.6014 & - & $0.35 \pm 0.06$ & - & - & - & 0.35 & 0.09 \\
\hline
\end{tabular}

$O_{a}^{\prime 2}$, direct additive genetic variance; $O_{m}^{\prime 2}$, maternal additive genetic variance; $O_{p e}^{\prime 2}$, maternal permanent environmental variance; $O_{e}^{2}$, residual variance; $O_{p}^{\prime 2}$, phenotypic variance; $\sigma_{a m}$, direct-maternal genetic (co) variance; $h_{a}^{2}$, direct heritability; $h_{m}^{2}$, maternal heritability; $p e^{2}$, environmental proportion of total variance; $r_{a m}$, direct-maternal correlation; $h_{T}^{2}$, total heritability; $t_{m}$, repeatability of ewe performance. BW, birth weight; WW, weight at weaning or at 60 days; W180, weight at 180 days; W270, weight at 270 days; DGW, daily weight gain at weaning; DGWS, daily weight gain from weaning to 6 months; DGSN, daily weight gain from 6 to 9 months; DGWN, daily weight gain from weaning to 9 months; HF, hair in fur; LM, leg muscularity.

Genetic parameters are important because of the significant information available from ewes and their progeny, allowing for the proper partitioning of genetic variance (Maniatis and Pollott, 2003). Direct heritability $\left(h^{2}{ }_{a}\right)$ oscillated between $0.22 \pm 0.04$ (BW) and $0.49 \pm$ 0.06 (W270), which are higher values than those reported in other studies (Magalhães et al., 2013; Boujenane et al., 2015; Gholizadeh and Ghafouri-Kesbi, 2015; Jannoune et al., 2015; Mohammadi et al., 2015), in which BW values were between 0.05 and 0.15 . However, in an analysis of Santa Ines sheep, Carvalho et al. (2014) obtained similar values to ours $(0.20 \pm$ 0.03), as did Hanford et al. (2003) and Zishiri et al. (2014) with a value of $0.25 \pm 0.04$ in both cases. The $h^{2}$ for WW was less than that for BW and subsequent time points, which increased at the post-weaning stages WW $(0.20 \pm 0.04)$, W180 $(0.39 \pm 0.07)$, and W270 $(0.49 \pm 0.06)$.

Genetics and Molecular Research 15 (3): gmr.15038910 
The remarkable variation observed in the performances of animals at these ages could have been caused by a direct genetic effect. This trend was similar, but not of the same magnitude, as that reported by Hanford et al. (2003), Magalhães et al. (2013), Mohammadi et al. (2015) and Valerio et al. (2015). Gowane et al. (2015) found that in Malpura sheep the $h^{2}$ for weight at 90, 180, and 270 days was 0.40, 0.50, and 0.37, respectively, whereas Shokrollahi and Baneh, (2012) found that in Iranian sheep these values were 0.38 (WW) and 0.19 (W180), and both studies reported a negative direct-maternal correlation.

Estimates of $h^{2}$ for daily weight gain at different ages (DGW, DGWS, DGSN, and DGWN) revealed a high degree of heritability $(0.38 \pm 0.06$ to $0.44 \pm 0.06)$. Gowane et al. (2015) obtained similar results in Malpura sheep. However, these data are not in agreement with those of Mohammadi et al. (2015), who reported low values in Lori sheep this discrepancy could be due to environmental effects. Other studies have also reported low to moderate values for weight gain at weaning and post-weaning of 0.07 and 0.22 , respectively (Magalhães et al., 2013; Tamioso et al., 2013; Oliveira et al., 2014; Shiotsuki et al., 2014; Valerio et al., 2015). Therefore, the phenotype of these traits in this sheep population exhibited additive genetic variance, and are good indicators for selection. A similar additive genetic effect was found for carcass traits and body size in Santa Ines sheep by Figueiredo Filho et al. (2016). HF $(0.28 \pm$ $0.05)$ and LM $(0.35 \pm 0.06)$ had moderately high heritability, similar values were obtained by ASCCO/USP (2011) in the same sheep population for HF (0.26) but not for LM (0.19), which was less heritable, indicating that more data improve the overall estimate.

The maternal effect is particularly important for early growth traits in sheep as it is influential during pregnancy and lactation, but its importance decreases during the postweaning stages (Shiotsuki et al., 2014; Zishiri et al., 2014; Gholizadeh and Ghafouri-Kesbi, 2015). The estimates of $h^{2}$ obtained for BW $(0.14 \pm 0.03)$, WW $(0.13 \pm 0.05)$ and DGW $(0.10$ $\pm 0.01)$ were sizeable, but were lower for W180 (0.05 \pm 0.02$)$. Santana et al. (2013) obtained similar results in an evaluation of various models in the same population of sheep, but using fewer data. In addition, Mohammadi et al. (2015) reported similar results in Lori sheep and Tamioso et al. (2013) in Suffolk sheep (BW, 0.17), as did Hanford et al. (2003) and Gowane et al. (2015) for WW (0.11 and 0.15, respectively), and Eler et al. (1995) for BW (0.12) and WW (0.13) in Nelore cattle.

Other authors (Zishiri et al., 2014; Gholizadeh and Ghafouri-Kesbi, 2015; Jannoune et al., 2015) found a low maternal additive effect for BW (0.05 to 0.09) and for WW, with the latter having values of between 0.02 (Zishiri et al., 2014; Gholizadeh and Ghafouri-Kesbi, 2015) and 0.07 (Boujenane et al., 2015). Estimates of greater magnitude have also been reported (Hanford et al., 2003; Lôbo et al., 2009; Shokrollahi and Baneh, 2012; Carvalho et al., 2014; Gowane et al., 2015; Valerio et al., 2015). Therefore, the magnitude of maternal influence depends upon the breed of the mother, and the Santa Ines breed has a significant maternal effect.

The proportions of dams in a permanent environment $\left(p e^{2}\right)$ in the analyzed traits, which is considered a maternal environmental effect, were of high magnitude $(\mathrm{BW}, 0.57 \pm 0.03$; WW, $0.60 \pm 0.03$; W180, $0.54 \pm 0.05$, and DGW, $0.48 \pm 0.05$ ). This may be attributable to an extensive grazing system that is available throughout the year, in which ewes have to endure changing environments during their reproductive lives. Therefore, it is important to consider this effect in populations with extensive grazing systems. Studies conducted on populations that were maintained in controlled environments have obtained low estimates (between 0.18 and 0.04) in comparison with our results (Hanford et al., 2003; Mandal et al., 2012; Zishiri et al., 2013, 2014; Boujenane et al., 2015; Gowane et al., 2015; Mohammadi et al., 2015).

Genetics and Molecular Research 15 (3): gmr.15038910 
Estimates of $h^{2}{ }_{T}$ were large in magnitude for all of the traits evaluated (WB, 0.38; WW, 0.29; W180, 0.43; W270. 0.49; DGW, 0.48; DGWS, 0.43; DGSN, 0.43; DGWN, 0.44; HF, 0.28 , and LM, 0.35), suggesting that individual selection can be applied to all of these traits. Crispim et al. (2013) showed that some Brazilian sheep breeds have relatively high levels of genetic diversity. Heritabilities that have been determined for other countries' sheep breeds were between low and moderate in magnitude: Shokrollahi and Baneh (2012) in Arabi sheep (BW, 0.16; WW, 0.13; and W180, 0.14) and Gowane et al. (2015) in Malpura sheep (BW, 0.21; WW, 0.15; W180, 0.17; W270, 0.11; DGW, 0.15; and DGWS, 0.045); in these studies, the $r_{a m}$ was negative. Valerio et al. (2015) reported that in Junin sheep (with $\mathrm{s}_{\mathrm{am}}=0$ in the model used), values of BW, WW, and DGW were $0.27,0.28$, and 0.29 , respectively. In other studies the maternal effect was not considered: Mandal et al. (2012) reported a DGW value of 0.26 in Muzaffarnagari sheep, and Boujenane et al. (2015) reported BW and WW values of 0.11 and 0.12 , respectively, in D'man sheep. These data support a statement made by Maniatis and Pollott (2003): the accuracy of the maternal effect and direct-maternal correlation will depend on the volume of pedigree information, and improved accuracy will influence the estimate of $h_{T}^{2}$

Significant positive values of $r$ were obtained with a gradual decrease as the lamb became independent of the mother (BW, 0.31; WW, 0.10; W180, 0.066; and DGW, 0.17). These data may indicate that, in addition to selecting for these characteristics, selection will also affect maternal ability. Gholizadeh and Ghafouri-Kesbi (2015) reported a positive $r_{a m}$ value in Baluchi sheep. Maniatis and Pollott (2003), Shokrollahi and Baneh (2012), Carvalho et al. (2014), Zishiri et al. (2014), Gowane et al. (2015), and Jannoune et al. (2015) obtained negative correlations for these traits. Several research groups suggest that negative correlations result in an overestimation of direct and maternal effects, and a decrease in the response of the other trait. In addition, using groups of dams with limited informational records and small numbers of progeny will result in negative correlation values (Maniatis and Pollott, 2003; Zishiri et al., 2014).

The repeatability of ewe performance $\left(\mathrm{t}_{\mathrm{m}}\right)$ is dependent upon the maternal effect and predicts the future performance of ewes. This parameter allows for the accurate identification and culling of less productive ewes, with a decreasing trend as the age of the animal increases. The estimates of $\mathrm{t}_{\mathrm{m}}$ obtained in this population were high for BW (0.82), WW (0.8), W180 (0.7), and DGW (0.61). Estimates in other populations of sheep are not comparable with respect to repeatability, due to the low and moderate values obtained. This discrepancy can be attributed to the model used or the negative $r_{a m}$ value obtained (Mandal et al., 2012; Gowane et al., 2015; Mohammadi et al., 2015). For the other post-weaning characteristics evaluated, which only included the direct effect, the values were significant (between 0.07 and 0.12 ). Kushwaha et al. (2009) obtained comparable estimates in Chokla sheep for post-weaning weights, with a range of 0.12 to 0.15. However, in Suffolk and Polypay sheep, Notter (1998) obtained estimates for post-weaning weight gain that were slightly lower $(0.05$ and 0.06$)$ than those obtained in this study.

\section{BVs and genetic trends}

The average BVs by year of birth during the study period (2003-2014) and the genetic changes produced in each of the evaluated characteristics are presented in Figure 1 .

Genetics and Molecular Research 15 (3): gmr.15038910 

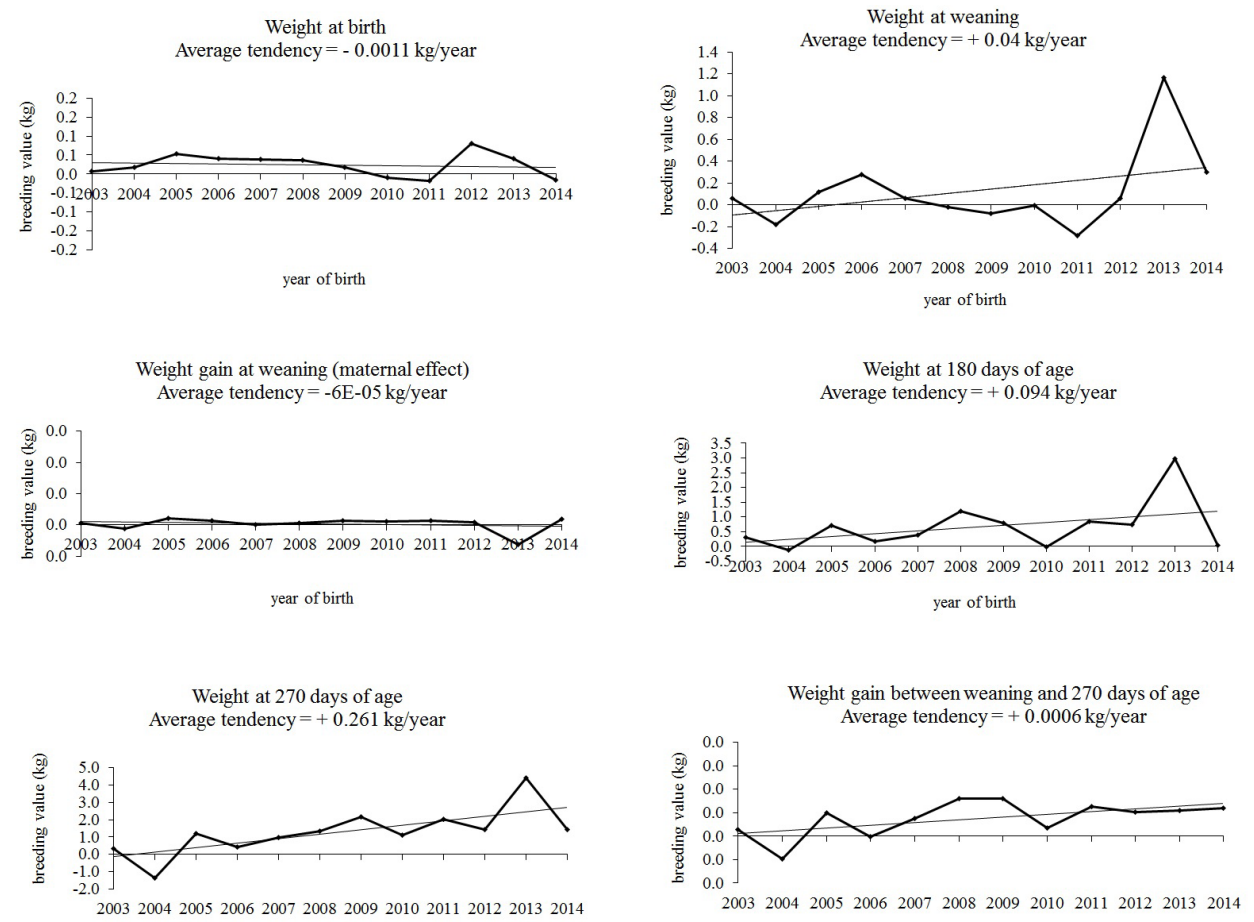

year of birth
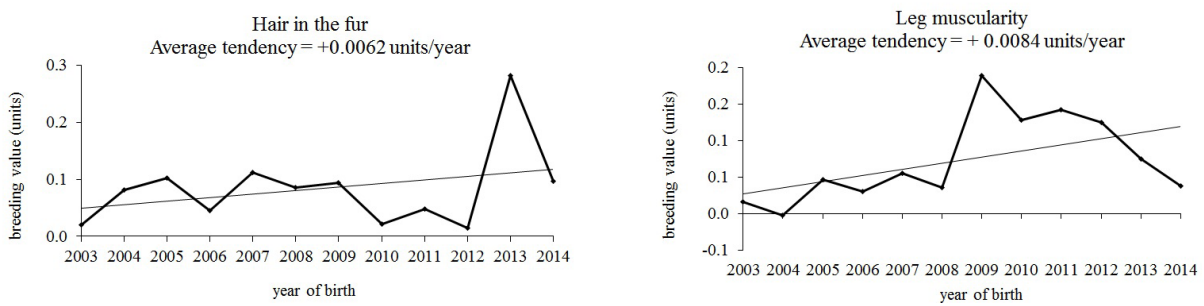

Figure 1. Genetic trends for birth weight, weaning, weight gain at weaning (maternal effect), weight at 180 and 270 days' age, weight gain between weaning and 270 days' age, presence of hair in fur, and leg muscularity in a population of Santa Ines sheep.

BV averages for BW exhibited a slightly negative genetic trend $(-0.001 \mathrm{~kg})$, suggesting that breeding does not affect this trait. A similar but lower trend $(-0.005 \mathrm{~kg})$ was found by Gholizadeh and Ghafouri-Kesbi (2015) in Baluchi sheep. The BVs for WW had an increasing trend of $0.04 \mathrm{~kg}$, but this was irregular as it decreased in some years (2004 and 2011), which indicates a lack of permanent selection. Comparing this observation with the results obtained by Gholizadeh and Ghafouri-Kesbi (2015) demonstrates that Santa Ines sheep perform better than other breeds. Average maternal BVs for DGW during the 12 years of this study did not increase, possibly due to a lack of ewe selection during this time, thereby wasting the maternal effect on this characteristic. 
The average BV for lamb weight at 180 and 270 days of age exhibited a positive genetic change, with increments of 0.094 and $0.24 \mathrm{~kg} / \mathrm{year}$, respectively. These data indicate that the process of breeding directly affected these traits. Trends obtained in Baluchi sheep by Gholizadeh and Ghafouri-Kesbi (2015) had smaller increments (W180, 0.004 kg; and W270, $0.007 \mathrm{~kg}$ ). The trend for weight gain between weaning and 270 days' age showed a slight increment $(0.0006 \mathrm{~kg} /$ year $)$, which could be improved with selection. There were positive improvements in HF and LM particularly in the later years of the study, and a continuation of this trend will benefit the production of this breed.

\section{CONCLUSIONS}

Our results show that Santa Ines sheep are amongst the heaviest "local" breeds, and exhibit significant genetic variance that manifests itself with age. A significant maternal effect and a permanent environmental effect were observed and cannot be ignored in similar genetic models, and a direct-maternal correlation was noted. We observed high values of total heritability for all of the traits analyzed and highly repeatable ewe performances. Several genetic trends were irregular and incremental, which may be due to variability in the selection of the goals and little continuity in process improvement. In conclusion, direct selection for pre-weaning traits enables the indirect selection for maternal ability. Depending upon the economic and productive purpose, selection based on any post-weaning traits should increase genetic progress.

\section{Conflicts of interest}

The authors declare no conflict of interest.

\section{ACKNOWLEDGMENTS}

We thank Associação Sergipana de Criadores de Caprinos e Ovinos (ASCCO) and Grupo de Melhoramento Animal e Biotecnologia, FZEA-USP, Pirassununga, SP, Brazil for providing the data-set. E.L. Aguirre thanks the Program of Alliances for Education and Training (PAEC-OEA-GCUB 2013) for a scholarship grant.

\section{REFERENCES}

ASCCO (2014) Associação Sergipana dos Criadores de Caprinos e Ovinos. Sergipe, Brasil. Available at [http://www. ascco.com.br]. Accessed May 2, 2014.

ASCCO/USP (2011) Sumario de Carneiros e Matrizes da Raça Santa Inês 2011. Programa de Melhoramento Genético da raça Santa Inês. GMA-FZEA-USP. Available at [http://www.usp.br/gmab/sumario/sumariocarneiros2011.pdf]. Accessed April 12, 2016.

Boldman KG, Kriese LA and Van Vleck LD (1995). A manual for use MTDFREML. A set of programs to obtain estimates of variances and covariances (DRAFT). Department of Agricultural Research Service-USDA, Lincoln, 120.

Boujenane I, Chikhi A, Ibnelbachyr M and Mouh FZ (2015). Estimation of genetic parameters and maternal effects for body weight at different ages in D'man sheep. Small Rumin. Res. 130: 27-35. http://dx.doi.org/10.1016/j. smallrumres.2015.07.025

Carvalho GC, Barbosa LT, de Oliveira TM, Fonseca FE, et al. (2014). Estimation of genetic parameters Santa Ines Sheep breed using single and two - trait models. Cienc. Rural 44: 111-116. http://dx.doi.org/10.1590/S0103$\underline{84782014000100018}$

Genetics and Molecular Research 15 (3): gmr.15038910 
Crispim BA, Grisolia AB, Seno LO, Egito AA, et al. (2013). Genetic diversity of locally adapted sheep from Pantanal region of Mato Grosso do Sul. Genet. Mol. Res. 12: 5458-5466. http://dx.doi.org/10.4238/2013.November.11.7

Dodenhoff J, Van Vleck LD and Gregory KE (1999). Estimation of direct, maternal, and grandmaternal genetic effects for weaning weight in several breeds of beef cattle. J. Anim. Sci. 77: 840-845.

Eler JP, Van Vleck LD, Ferraz JB and Lôbo RB (1995). Estimation of variances due to direct and maternal effects for growth traits of Nelore cattle. J. Anim. Sci. 73: 3253-3258.

Figueiredo Filho LA, Do Ó AO, Sarmento JL, Santos NP, et al. (2016). Genetic parameters for carcass traits and body size in sheep for meat production. Trop. Anim. Health Prod. 48: 215-218. http://dx.doi.org/10.1007/s11250-015-0921-5

Gholizadeh M and Ghafouri-Kesbi F (2015). Estimation of genetic parameters for growth-related traits and evaluating the results of a 27-year selection program in Baluchi sheep. Small Rumin. Res. 130: 8-14. http://dx.doi.org/10.1016/j. smallrumres.2015.07.032

Gowane GR, Prince LL, Lopes FB, Paswan C, et al. (2015). Genetic and phenotypic parameter estimates of live weight and daily gain traits in Malpura sheep using Bayesian approach. Small Rumin. Res. 128: 10-18. http://dx.doi. org/10.1016/j.smallrumres.2015.04.016

Graser HU, Smith SP and Tier B (1987). A derivative free approach for estimating variance components in animal model by restricted maximum likelihood. J. Anim. Sci. 64: 1362-1370.

Hanford KJ, Van Vleck LD and Snowder GD (2003). Estimates of genetic parameters and genetic change for reproduction, weight, and wool characteristics of Targhee sheep. J. Anim. Sci. 81: 630-640.

Jannoune A, Boujenane I, Falaki M and Derqaoui L (2015). Genetic analysis of live weight of Sardi sheep using random regression and multi-trait animal models. Small Rumin. Res. 130: 1-7. http://dx.doi.org/10.1016/j. smallrumres.2015.06.015

Kushwaha BP, Mandal A, Arora AL, Kumar R, et al. (2009). Direct and maternal (co)variance components and heritability estimates for body weights in Chokla sheep. J. Anim. Breed. Genet. 126: 278-287. http://dx.doi.org/10.1111/j.1439$\underline{0388.2008 .00771 . x}$

Lôbo AM, Lôbo RN, Paiva SR, de Oliveira SM, et al. (2009). Genetic parameters for growth, reproductive and maternal traits in a multibreed meat sheep population. Genet. Mol. Biol. 32: 761-770. http://dx.doi.org/10.1590/S1415$\underline{47572009005000080}$

Magalhães AF, Lobo RN and Faco O (2013). Genetic parameters estimates for growth traits in Somalis Brasileira hair sheep breed. Cienc. Rural 43: 884-889.

Mandal A, Dass G and Rout PK (2012). Model comparisons for estimation of genetic parameters of pre-weaning daily weight gains in Muzaffarnagari sheep. Small Rumin. Res. 106: 118-124. http://dx.doi.org/10.1016/j. smallrumres.2012.03.015

Maniatis N and Pollott GE (2002). Genotype by environment interactions in lamb weight and carcass composition traits. J. Anim. Sci. 75: 3-14.

Maniatis N and Pollott GE (2003). The impact of data structure on genetic (co)variance components of early growth in sheep, estimated using an animal model with maternal effects. J. Anim. Sci. 81: 101-108.

Mohammadi K, Abdollahi-Arpanahi R, Amraei F, Mohamadi EM, et al. (2015). Genetic parameter estimates for growth and reproductive traits in Lori sheep. Small Rumin. Res. 131: 35-42. http://dx.doi.org/10.1016/j.smallrumres.2015.07.029

Notter DR (1998). Genetic parameters for growth traits in Suffolk and Polypay sheep. Livest. Prod. Sci. 55: 205-213. http://dx.doi.org/10.1016/S0301-6226(98)00141-9

Oliveira DP, Oliveira CA, Martins EN, Vargas Jr F, et al. (2014). Genetic parameters of performance traits in Sul-MatoGrossenses naturalized sheep. Ciências Agrárias, Londrina. 35: 963-972.

R Core Team (2016). R: A language and environment for statistical computing. R Foundation for Statistical Computing, Vienna, Austria. Available at [https://www.R-project.org/].

Santana Jr ML, Bignardi AB, Eler JP, Cardoso FF, et al. (2013). Genotype by environment interaction and model comparison for growth traits of Santa Ines sheep. J. Anim. Breed. Genet. 130: 394-403.

Shiotsuki L, de Oliveira DP, Lobo RN and Faco O (2014). Genetic parameters for growth and reproductive traits of Morada Nova sheep kept by smallholder in semi-arid Brazil. Small Rumin. Res. 120: 204-208. http://dx.doi.org/10.1016/j. $\underline{\text { smallrumres.2014.05.009 }}$

Shokrollahi B and Baneh H (2012). (Co)variance components and genetic parameters for growth traits in Arabi sheep using different animal models. Genet. Mol. Res. 11: 305-314. http://dx.doi.org/10.4238/2012.February.8.5

Silva LS, Fraga AB, da Silva FD, Beelen PM, et al. (2012). Growth curve in Santa Ines sheep. Small Rumin. Res. 105: 182-185. http://dx.doi.org/10.1016/j.smallrumres.2011.11.024

Szwaczkowski T, Wojtowski J, Stanislawska E and Gut A (2006). Estimates of maternal genetic and permanent environmental effects in sheep. Arch. Tierz. 49: 186-192.

Genetics and Molecular Research 15 (3): gmr.15038910 
Tamioso PR, Alberti JL, Dias LT and Teixeira RD (2013). Estimates of (co)variance components and genetic parameters for growth traits in Suffolk lambs. Cienc. Rural 43: 2215-2220. http://dx.doi.org/10.1590/S0103-84782013001200016

Valerio D, Gutiérrez G and Chávez J (2015). Direct and maternal genetic effects on the growth of Junín sheep breed. Rev. Inv Vet Perú. 26: 28-35. http://dx.doi.org/10.15381/rivep.v26i1.10921

Willham RL (1972). The role of maternal effects in animal breeding. 3. Biometrical aspects of maternal effects in animals. J. Anim. Sci. 35: 1288-1293.

Zishiri OT, Cloete SW, Olivier JJ and Dzama K (2013). Genetic parameters for growth, reproduction and fitness traits in the South African Dorper sheep breeds. Small Rumin. Res. 112: 39-48. http://dx.doi.org/10.1016/j. smallrumres.2013.01.004

Zishiri OT, Cloete SW, Olivier JJ and Dzama K (2014). Genetic parameters for live weight traits in South African terminal sire sheep breeds. Small Rumin. Res. 116: 118-125. http://dx.doi.org/10.1016/j.smallrumres.2013.11.005

Genetics and Molecular Research 15 (3): gmr.15038910 